\title{
Gestão de estratégias: uma proposta de modelo para os governos locais
}

\author{
Francine Lia Wosniak \\ Pontifícia Universidade Católica do Paraná \\ Denis Alcides Rezende \\ Pontifícia Universidade Católica do Paraná
}

\begin{abstract}
Os governos são pressionados no sentido de adequar suas instituições e modos de agir ao contexto de um mundo cada vez mais questionador, globalizado, complexo e interdependente. Esses desafios e transformações requerem inovadores modelos públicos de gestão, assim como efetivos instrumentos, procedimentos e formas de ação. O objetivo deste estudo é propor um modelo de gestão de estratégia, tendo por base analítica as gestões municipais de Curitiba, no período de 1993 a 2008. Para a efetivação da resposta a essa demanda realizou-se um estudo de caso, estruturado por meio de um protocolo de pesquisa, com a definição de categorias e subcategorias de análise. A análise descritiva foi subsidiada pela base teórica deste estudo, a qual se fundamentou nos temas gestão municipal e administração estratégica. Os principais resultados auferidos estão relacionados com as etapas do processo de administração estratégica implementadas nas gestões e seus respectivos descritores. A conclusão possibilitou a proposição de um modelo de gestão da estratégia, resultante da combinação das categorias de análise que compuseram este estudo, e que representa, em sua concepção, uma alternativa de implementação do processo de gestão.
\end{abstract}

Palavras-chave: gestão municipal; administração estratégica; processos municipais.

\section{Strategies management: a proposal of a model for the local governments}

The governments are pressured to adapt their institutions and type of action to the context of an increasingly questioning, globalized, complex and interdependent world. These challenges and transformations require innovative public management models, as well as effective tools, procedures and types of action. The objective of this study is to propose a strategy management model, having as its analytical basis the municipal management of Curitiba, in the period from 1993 to 2008. To obtain the answer to this demand, we performed a case study, structured through a research protocol, with the definition of categories and subcategories of analysis. The descriptive analysis was subsidized by the theoretical basis of this study, which was based on the themes municipal management and strategic administration. The main results obtained are related to the phases of the process of strategic admi-

Artigo recebido em 5 jun. 2009 e aceito em 14 jul. 2011. Os autores agradecem ao CNPq. 
nistration implemented in the management periods and their respective descriptors. The conclusion allowed the proposition of a strategic management model, resulting from the combination of analysis categories that formed this study, and which represents, in its conception, an alternative of implementation of the management process.

KeY WORDs: municipal management; strategic administration; municipal processes.

\section{Introdução}

O debate sobre a administração pública tem ocupado importante espaço na agenda internacional, nos fóruns de discussão e nas diversas publicações especializadas sobre o contexto contemporâneo de transformação do Estado e da sociedade. Na verdade, tal situação não representa algo novo, pois a reforma da administração pública está em curso desde que existe administração pública. O debate sobre a gestão pública ainda se confunde, na maior parte dos casos, com o debate sobre o Estado, embora nem sempre seguindo o mesmo ritmo. Alguns estudiosos argumentam que as mudanças nas formas de regime político do Estado acontecem num ritmo mais acelerado do que as mudanças nas formas de administração pública (Marini, 2003). O mundo se transformou de modo veloz nas duas últimas décadas e os governos burocráticos, com características lentas e lineares por natureza, começaram a se tornar inadequados e ineficientes. A qualidade do governo, nessa perspectiva, é o ponto central da competitividade do Estado. O perfil requerido das organizações, inclusive dos governos, na "Era da Informação", é composto por organizações enxutas, flexíveis, que trabalhem por meio de parcerias, com foco nas necessidades do cliente, inovadoras e em permanente evolução (Machado, 2001). A falta de métodos, instrumentos e procedimentos adequados na administração pública, em nível municipal, exige transformações urgentes. O processo, nesse sentido, ainda é lento quando comparado às mudanças macroeconômicas (Pfeiffer, 2000). Tais transformações indicam a necessidade de alterações de estruturas, regras e processos, demandando uma postura mais flexível, criativa e empreendedora (Matias-Pereira, 2008).

O século XXI parece estar se dirigindo para uma reabilitação da pólis, da cidade. Num contexto marcado por dificuldades e conturbações, as cidades que compreenderem que se tornaram o centro das atividades econômicas, culturais, sociais, políticas e adotarem, tanto no plano político como no administrativo, as estruturas e os modelos à altura de suas novas responsabilidades contribuirão sobremaneira para o bem-estar de seus munícipes. A presença do município na vida dos cidadãos, desde as antigas reformulações da cidade-estado até as contemporâneas, aponta para a importância de uma melhor gestão nessa esfera de governo. Assim, a dinâmica do governo municipal, eficiente, eficaz e democrático, se constitui ambição a alcançar (Fachin e Chanlat, 1998).

No mundo contemporâneo, a mudança assume velocidade nunca vista. Se, no início do século passado, o que antes ocorria em um século passou a ocorrer em uma década, hoje, o que acontecia em décadas passou a acontecer em segundos (Vergara, 2004). Uma das consequências marcantes da época de crise que atravessamos é a redescoberta da influência que o município pode ter na vida dos cidadãos. Vislumbra-se que a maioria da população vive atual- 
mente em grandes centros urbanos, os quais devem prover os serviços básicos que ela espera receber. Diferentemente do que ocorre nas instâncias regionais, nacionais e mais recentemente supranacionais, onde é possível refugiar-se impunemente na abstração, a proximidade dos cidadãos no nível municipal não dá espaços para fugas (Fachin e Chanlat, 1998). A gestão pública demandada pelo novo modelo requer maior democratização de centros decisórios, modernização e flexibilidade de suas estruturas, métodos e processos, descentralização de ações e poder, abertura externa, velocidade e maleabilidade, cujos atributos permitem responder à aceleração das mudanças nas condições socioeconômicas, sociopolíticas e culturais. Essas transformações, por sua vez, remetem aos governantes e gestores a necessidade de aperfeiçoar os meios de coordenar e integrar ações de governo, abandonando as formas carismáticas e autoritárias, dependentes da unicidade e da hierarquia de comando para alcançar a eficiência e a eficácia desejáveis (Costa e Cunha, 2004).

Nesse contexto, as organizações são pressionadas por elevada competitividade, exigência quanto à qualidade dos serviços prestados e expectativa por resultados. Além do aumento de produtividade, se espera flexibilidade, criatividade e melhoria de desempenho, de modo a contemplar as necessidades e interesses dos clientes-cidadãos. Para atender essa demanda, as organizações precisam inovar constantemente, visto que o ritmo das mudanças e dos novos conhecimentos e informações geram transformações na sociedade, criam novas expectativas, novos cenários, novos desafios (Sveiby, 1998).

Na concepção de Figueiredo e Lamounier (1996), o ambiente de hoje, em rápida mutação, exige instituições que consigam produzir bens e serviços de alta qualidade, extraindo ao mesmo tempo cada vez mais de cada centavo. Exige instituições que reajam às necessidades de seus clientes, oferecendo opções de serviços não padronizados; instituições que consigam liderar através da persuasão e dos incentivos, e não através de ordens; que deem aos funcionários um sentido de significado e controle, até mesmo de propriedade. Evidencia-se, assim, que os recursos cresceram, porém as dificuldades também.

As cidades necessitam de modelos de gestão inovadores para que os gestores urbanos tratem das mudanças que a sociedade globalizada exige. Com as profundas mudanças globais, sociais, econômicas e políticas, as cidades estão requerendo novos e inovadores modelos de gestão, assim como novos instrumentos, procedimentos e formas de ação, a fim de permitir que os gestores urbanos tratem das mudanças de uma sociedade globalizada. Por um lado, é necessário encontrar respostas e soluções rápidas para problemas cujas causas ficam muitas vezes fora da esfera de influência do administrador público, mas cujas consequências precisam ser enfrentadas pelo poder local. Por outro, é uma tarefa essencial explorar e disponibilizar as chances e oportunidades relacionadas a tais transformações, em favor tanto da administração pública quanto da própria população (Rezende e Frey, 2005).

Identificar e compreender como a administração estratégica pode se constituir num processo facilitador da gestão municipal nesse cenário determinam o caminho a ser perseguido neste estudo. Diante desse contexto, constitui objetivo deste artigo propor um modelo de gestão de estratégia, concebido como ferramenta de gestão para os governos locais, resultante da combinação das categorias e subcategorias que compuseram este estudo. Tais categorias ou variáveis de análise foram definidas tendo por base as etapas do processo de administração estratégica e se encontram assim constituídas: formulação das estratégias; formalização das 
estratégias; análises estratégicas do ambiente; diretrizes organizacionais; implementação das estratégias e controles estratégicos.

A relevância e a atualidade deste estudo residem no sentido de contribuir para a disseminação e o compartilhamento de conhecimentos e experiências em gestão de estratégias, numa perspectiva de enfrentamento aos crescentes desafios impostos aos governos locais.

\section{Fundamentação teórica}

Tendo por elemento balizador o objetivo definido, a base teórica fundamentou-se nas temáticas gestão municipal e administração estratégica.

\subsection{Gestão municipal e urbana}

No mundo contemporâneo a principal função do Estado é a ampliação, de modo sistemático, das oportunidades individuais, institucionais e regionais. Para Matias-Pereira (2008:116),

o Estado pode ser concebido enquanto lócus no qual o cidadão exerce a cidadania. Dessa forma, todos os esforços devem convergir para a melhoria da qualidade da prestação dos serviços públicos na perspectiva de quem o utiliza e oportunizar o aprendizado social de cidadania. A partir das escolhas da sociedade quanto à configuração do Estado que se deseja, são direcionados os limites e as possibilidades da gestão pública demandada, seu modelo, suas práticas e seus valores.

O ambiente mundial, neste final de século XX, está marcado por importantes transformações, em meio às quais algumas tendências se tornam cada vez mais hegemônicas. Entre elas, a tendência à globalização dos fluxos comerciais, produtivos, tecnológicos e financeiros, sob o comando de verdadeiros atores globais. A mobilidade desses fluxos globalizados impõe inovadores desafios aos atores que atuam em espaços locais (Neto e Araújo, 1998). Nesse ambiente, a globalização tem se revelado processo não antagônico - muito ao contrário, perfeitamente compatível — com movimentos de descentralização. Os espaços locais vêm, assim, ganhando crescente relevância. As cidades passam a ser concebidas como atores políticos relevantes, capazes de assumir a centralidade das ações de intervenções nas diferentes esferas da vida social e de atuar como elo de articulação entre a sociedade civil, a iniciativa privada e diferentes instâncias do Estado (Castells e Borja, 1996).

O conceito de gestão, da ótica da administração, está relacionado com o conjunto de recursos e a aplicação de atividades destinadas ao ato de gerir. O processo de gestão é uma função orgânica básica da administração. São processos mentais e físicos de estabelecer o que é desejável e como será elaborado. Gestão é fazer administração nas organizações. Procura reunir planejamento estratégico e administração em um único processo (Mintzberg e Quinn, 2001).

A gestão municipal pode ser considerada a administração pública dos bens e interesses municipais e é executada pelo gestor municipal por meio da atividade administrativa, atos de gestão, os quais devem estar de acordo com os princípios básicos da administração pública, 
quais sejam: legalidade, moralidade, impessoalidade, publicidade, eficiência, razoabilidade, proporcionalidade, ampla defesa, contraditório, segurança jurídica, motivação e supremacia dos interesses públicos (Castro Junior, 2008).

A gestão municipal permite transparência no uso de recursos públicos, uma vez que determina previamente os resultados a obter com o uso daqueles recursos, bem como os indicadores para mensurar o desempenho institucional (Pacheco, 1999; Pfeiffer, 2000). Após a Reforma do Estado e o advento da Lei de Responsabilidade Fiscal, reforça a necessidade de considerar o planejamento como a ferramenta com maior significado (Pfeiffer, 2000; Rossi et al., 2004). Para Rezende e Castor (2006), gestão municipal pode ser entendida como gestão da prefeitura e de seus órgãos, institutos, autarquias e secretarias. Está relacionada com o conjunto de recursos e instrumentos da administração aplicado na administração local, por meio de seus servidores municipais. No que se refere ao planejamento municipal, a gestão municipal enfatiza o planejamento estratégico municipal. Já a gestão urbana pode ser entendida como a gestão da cidade. Está relacionada com o conjunto de recursos e instrumentos da administração aplicados na cidade como um todo, visando à qualidade da infraestrutura e dos serviços urbanos, propiciando melhores condições de vida e aproximando os cidadãos nas decisões e ações da governança pública municipal. No que diz respeito ao planejamento municipal, a gestão urbana enfatiza o plano diretor da cidade (Rezende e Castor, 2006).

Sob a ótica da ciência social, a gestão urbana é concebida como estratégias de desenvolvimento urbano (Souza, 2002). Tem por prática desafiadora a adoção de uma visão sistêmica da gestão urbana, incluindo em suas análises as dimensões social, econômica, política, administrativa, cultural, ambiental e tecnológica (Frey, 2003; Castro Junior, 2008).

Compete à gestão urbana a garantia do funcionamento de uma cidade em seus quatro aspectos principais, quais sejam: habitação, trabalho, lazer e circulação. Implica, primeiramente, uma máquina administrativa, ou seja, espaços físicos, equipamentos e recursos humanos, os quais se encontram organizados em instituições. Em segundo lugar, implica serviços básicos, tais como saneamento, educação, saúde, habitação, lazer, segurança, transporte, energia. Em terceiro lugar, e para que esses serviços e instituições possam cumprir essas demandas de maneira eficiente, é necessário viabilizar a arrecadação de recursos financeiros, se fazendo valer da legislação para conceder legalidade aos atos administrativos (Stoker, 2000; Silva Junior, Leal e Shigunov, 2004).

\subsection{Administração estratégica}

Em decorrência das transformações na economia mundial e nas conjunturas sociopolíticas que determinaram novas configurações de caráter geopolítico, a administração estratégica deixou de ser uma característica inerente e exclusiva de organizações empresariais de caráter assumidamente privado. É cada vez mais frequente sua adoção nas esferas públicas de gestão, refletindo uma crescente tendência de revisão das práticas administrativas internas como forma de se obter ganhos em termos de tempo, efetividade nas ações e otimização dos serviços prestados à comunidade. Da mesma forma, os cidadãos tornam-se mais exigentes quanto à qualidade dos serviços ofertados e requerem maior autonomia no trabalho. As demandas 
são constantemente renovadas, o que justifica a necessidade de organizações públicas cada vez mais flexíveis, adaptáveis, inovadoras e centradas no usuário (Souza, Rezende e Hardt, 2007). A administração estratégica emergiu como uma parte do planejamento, que atualmente é considerado um de seus principais instrumentos e surgiu como uma de suas etapas - a de seleção de caminhos a serem trilhados e das ameaças e oportunidades diagnosticadas em seu ambiente de atuação. Como uma evolução do planejamento estratégico, a gestão estratégica surgiu com um corpo teórico mais amplo, com a comunicação de uma visão estratégica global da empresa para os diversos níveis funcionais, com o objetivo de que as iniciativas da empresa sejam coerentes com a diretriz geral (Meirelles e Gonçalves, 2001).

O processo de administração estratégica visa manter uma organização como um conjunto integrado ao seu ambiente, num processo evolutivo, contínuo e iterativo. Esse significado conduz, no seu escopo, à ideia de que a administração estratégica é, sobretudo, a administração da mudança. Nesse sentido, a administração estratégica pode ser resumida em etapas inter-relacionadas e interdependentes, que a alta administração deve realizar e apoiar, conforme os itens a seguir: análise de ambiente externo - verificando as oportunidades e ameaças ou limitações; análise de ambiente interno — pontos fortes e fracos; estabelecimento de missão organizacional e dos objetivos gerais; formulação de estratégias em todos os níveis, que permitam à organização combinar seus pontos fortes e fracos com as oportunidades do ambiente; implementação de estratégias; e realização de atividades de controle estratégico. Um dos produtos finais da administração estratégica é um potencial de cumprimento futuro dos objetivos da organização. Isso envolve recursos, produtos finais de rentabilidade futura comprovada e um conjunto de regras de comportamento social que permitam à organização continuar a alcançar seus objetivos (Ansoff e McDonnell, 1993).

Na sequência serão fundamentadas as fases ou etapas clássicas que compõem o processo de administração estratégica, as quais constituíram as categorias de análise deste estudo, assim constituídas: formulação da estratégia (priorizaram-se o conteúdo e o processo da formulação da estratégia, segundo a concepção de diferentes autores, contextos e perspectivas); formalização das estratégias (cujo objetivo foi possibilitar a identificação da existência do planejamento, bem como dos procedimentos metodológicos adotados e suas respectivas fases); análises estratégicas do ambiente (cujo foco de estudo e análise investigativa foi o diagnóstico municipal); diretrizes organizacionais (com ênfase na missão e nos objetivos estratégicos organizacionais); implementação da estratégia (com vistas a possibilitar a análise comparativa neste estudo, optou-se em concentrar a investigação em três estratégias operacionais — intersetorialidade, descentralização e participação social); e controles estratégicos (com ênfase nos mecanismos e instrumentos de monitoramento e avaliação da gestão).

\subsubsection{Formulação da estratégia}

O uso e a aplicação do conceito de estratégia na literatura gerencial têm se disseminado à medida que aumentam os desafios e exigências de mudanças, transformações e ajustes dos 
sistemas de produção e gestão diante das novas situações sociais, políticas, econômicas ou tecnológicas (Motta, 1997). Estratégia pode ser conceituada como a determinação das metas e dos objetivos básicos de uma empresa para o longo prazo, assim como a adoção de cursos de ação e a alocação dos recursos necessários para atingi-los. Visa criar uma posição valiosa e exclusiva, envolvendo um diferente conjunto de atividades (Chandler, 1962; Christensen, 1999; Porter, 1999).

A estratégia pode ser concebida como um padrão ou um plano que integra de uma forma coesa os objetivos, a missão, as políticas e as ações de uma organização. Compreende um dos vários conjuntos de regras de decisão para orientar o comportamento da organização, vista como uma ferramenta para trabalhar com as turbulências e as condições de mudanças que permeiam as organizações (Ansoff, 1983; Wright, Kroll e Parnell, 2000).

As decisões antecipadas de o que fazer, o que não fazer, de quando fazer, de quem fazer, de quais recursos são necessários para atingir alvos num tempo predefinido podem ser chamadas de estratégia (Oliveira, 2003). A ideia mais simples de estratégia pode ser resumida como a arte de planejar, compreendendo um dos vários conjuntos de regras de decisão para orientar o comportamento da organização, vista como uma ferramenta para trabalhar com diferentes e divergentes condições (Ansoff e McDonnell, 1993). É uma forma de pensar no futuro, integrada no processo decisório, com base em um procedimento formalizado e articulador de resultados e em uma programação. Mas, na prática, uma relação pode complementar a outra e estratégia e tática podem ser vistas de formas diferentes pelos diversos envolvidos no município, conforme a escala ou perspectiva de ação (Mintzberg e Quinn, 2001). A estratégia, numa visão mais operacional, define-se como a decisão sobre o recurso que deve ser adquirido e utilizado a fim de possibilitar a potencialização das oportunidades e a minimização dos fatores que ameaçam a consecução dos resultados desejados. É a mobilização de todos os recursos da organização no âmbito nacional ou internacional visando atingir objetivo a longo prazo, com flexibilidade de resposta às contingências imprevisíveis (Michel, 1990; Lodi, 1969).

A estratégia deve ser usada para gerar projetos estratégicos por meio de um processo de busca. O papel da estratégia nesse contexto é, primeiramente, focalizar a atenção em áreas por ela definidas e, em segundo lugar, identificar e eliminar possibilidades que com ela sejam incompatíveis. É uma ferramenta para lidar com as condições de mudança que cercam a organização na atualidade. Oferece importante auxílio para lidar com as turbulências enfrentadas pelas organizações, a perda de relevância sentida pelas universidades, a deterioração de organismos de cumprimento da lei, o declínio de sistemas de apoio à saúde, o congestionamento urbano (Ansoff e McDonnell, 1993).

Ao considerar os estágios diferentes do desenvolvimento da administração estratégica, Mintzberg, Ahlstrand e Lampel (2000) propuseram 10 escolas de pensamento sobre formulação da estratégia, cujas visões referentes ao seu processo podem ser resumidas conforme demonstrado no quadro 1. 
Quadro 1

\section{Processo da formulação de estratégia na visão das 10 escolas}

\begin{tabular}{|ll|}
\hline \multicolumn{1}{|c|}{ ESCOLAS } & \\
\hline Escola do Design & Formulação da estratégia como um processo de concepção \\
Escola do Planejamento & Formulação da estratégia como um processo formal \\
Escola do Posicionamento & Formulação da estratégia como um processo analítico \\
Escola Empreendedora & Formulação da estratégia como um processo visionário \\
Escola Cognitiva & Formulação da estratégia como um processo mental \\
Escola de Aprendizado & Formulação da estratégia como um processo emergente \\
Escola do Poder & Formulação da estratégia como um processo de negociação \\
Escola Cultural & Formulação da estratégia como um processo coletivo \\
Escola Ambiental & Formulação da estratégia como um processo reativo \\
Escola da Configuração & Formulação da estratégia como um processo de transformação \\
\hline
\end{tabular}

Fonte: Elaborada pelos autores com base em Mintzberg, Ahlstrand e Lampel (2000).

Tais escolas surgiram em estágios diferentes do desenvolvimento da administração estratégica e podem ser agrupadas da seguinte forma: as três primeiras são de natureza prescritiva, ou seja, mais preocupadas em como as estratégias devem ser formuladas do que em como elas são formuladas. As seis escolas seguintes consideram aspectos específicos do processo de formulação das estratégias e têm-se preocupado menos com a prescrição do comportamento estratégico ideal do que como as estratégias são, de fato, formuladas. O último agrupamento contém apenas uma escola, embora seja possível argumentar que essa escola, na realidade, combina as outras. Em busca da integração, tais escolas agrupam o processo de formulação de estratégias, o conteúdo das mesmas, as estruturas organizacionais e seus contextos (Mintzberg, Ahlstrand e Lampel, 2000).

A essência da formulação estratégica é lidar com a competição. Qualquer que seja seu esforço coletivo, o objetivo estratégico da organização é encontrar uma posição em que ela possa melhor se defender das forças combatentes e ameaças ou influenciá-las em seu benefício. O conhecimento dessas fontes básicas de pressão competitiva propicia o trabalho preliminar para uma agenda estratégica de ação. Elas acentuam os esforços críticos e os pontos fracos da organização, dão vida ao seu posicionamento no setor, tornam claras as áreas onde as mudanças estratégicas possam oferecer maiores vantagens e acentuam os lugares onde as tendências do setor prometem ser da maior importância, seja como oportunidade, seja como ameaça. Uma vez analisadas as forças que afetam a competição em um setor e suas causas básicas, o estrategista corporativo pode identificar o vigor e as fraquezas da empresa. Pode então divisar um plano de ação, o qual poderá incluir o posicionamento da empresa de tal modo que suas capacitações forneçam a melhor defesa contra a força competitiva; ou influenciar no equilíbrio de forças por meio de ações estratégicas, melhorando, portanto, a posição da empresa (Montgomery e Porter, 1998). 
Para fins de realização deste estudo, optou-se pelo conceito de estratégia como um padrão ou um plano que integra de forma coesa os objetivos, as políticas e as ações da organização. Pressupõe a adoção de cursos de ação e a alocação dos recursos necessários para atingir essas metas, com um diferente conjunto de atividades (Mintzberg e Quinn, 2001; Chandler, 1962; Porter, 1999).

\subsubsection{Formalização das estratégias}

As atuais estruturas administrativas em nível local e os procedimentos e instrumentos vigentes encontram-se entre os maiores obstáculos no caminho para um gerenciamento urbano moderno e dinâmico, o qual seria capaz de lidar adequadamente com os processos atuais. O planejamento urbano não pode mais ficar limitado à abrangência do próprio município. Torna-se necessária a criação de novas oportunidades, fato não considerado pelos tradicionais instrumentos de planejamento urbano (Pfeiffer, 2000). O planejamento estratégico de cidades busca uma visão de futuro, a partir da realidade atual, que permita evoluir dentro de condições preestabelecidas de modo a qualificar a sociedade urbana para a superação dos desafios impostos. Desenvolveu-se em decorrência da necessidade de compatibilizar os desafios gerados pela atual estruturação da sociedade urbana com a administração dos espaços locais. Considera a comunidade local enquanto ator ativo e participante inserido em sua dinâmica e mantém como premissas: promoção da organização comunitária para o planejamento estratégico; descentralização; participação; continuidade administrativa das ações estratégicas; e desenvolvimento sustentável (Lopes, 1998; Pagnoncelli e Aumond, 2004).

Lopes (1998) considera quatro pontos principais no processo de planejamento estratégico, quais sejam: a missão, onde queremos ir; as estratégias, como chegar lá; o orçamento, o que podemos fazer; e o controle, como medir o andamento do processo. Por ser muito compreensivo e detalhado, a dificuldade gerada torna muitas vezes difícil manter o foco necessário a um planejamento estratégico bem-sucedido, principalmente no caso de organizações grandes e complexas. O planejamento constitui o método adotado por governos que desejam evitar a improvisação e dar atenção aos problemas prioritários do município, tendo uma dimensão técnica e outra política. A primeira implica o domínio de uma metodologia específica de trabalho pela sistematização de informações atualizadas e, frequentemente, o apoio dos conhecimentos especializados de profissionais de diferentes áreas. A segunda constitui um processo de negociação que procura conciliar valores, prioridades, necessidades e interesses divergentes e administrar conflitos entre os vários segmentos da sociedade que anseiam pelos benefícios da ação governamental (Cabral, 1996).

De acordo com Motta (2004), a eficiência da reflexão e do planejamento estratégico depende mais da capacidade inovadora e criadora de novas possibilidades e visão do que da capacidade analítica ou intuitiva de perseguir caminhos já trilhados. Planejamento é uma forma de aprendizado, por meio do qual se aprende sobre as demandas e necessidades externas e sobre a capacidade de resposta da administração municipal (Motta, 2004). 


\subsubsection{Análises estratégicas do ambiente}

Também chamadas de diagnósticos municipais, as análises estratégicas procuram identificar qual a real situação da cidade, de seu entorno e de sua administração, incluindo variáveis internas e externas. Procura-se verificar aspectos positivos e negativos, bem como formalizar o que o município tem de bom, de regular ou de ruim. Os dados, os indicadores e as informações da cidade e os conhecimentos dos cidadãos são recursos imprescindíveis para a elaboração das análises estratégicas da cidade e da administração municipal (Rezende e Castor, 2006). O diagnóstico tem como principal objetivo estabelecer uma visão comum e compartilhada pelos atores sociais sobre a situação de determinado território. O processo para eleger a identificação comum dos aspectos críticos e determinantes é um dos principais desafios do diagnóstico estratégico municipal, visto que em uma comunidade existem diferentes pontos de vista, enfoques e percepções sobre a mesma realidade (Llona, Luyo e Melgar, 2003).

São partes fundamentais do diagnóstico estratégico da cidade para seu planejamento municipal. Podem ser utilizadas múltiplas técnicas que permitem identificar e monitorar as variáveis necessárias para a performance da cidade e se constituem em etapa fundamental nos estudos do processo da administração estratégica (Certo e Peter, 1993; Mintzberg e Quinn, 2001; Wright, Kroll e Parnell, 2000). Devem se concentrar naqueles temas críticos que se manifestam no ambiente, sobre os quais a organização possui governabilidade. Nessa análise, não devem ser considerados apenas problemas, ameaças e oportunidades existentes, mas também as possibilidades de reação a eles, tratando-se, portanto, tanto de uma análise de problemas como de uma análise de potenciais. A construção de um banco de dados é uma das propostas mais frequentes, deixado de lado o fato de que o planejamento estratégico não pretende ser um planejamento detalhado, uma vez que se concentra nos problemas e fenômenos mais emergentes e claramente tangíveis. Além disso, tratando-se de fenômenos novos, é muito provável que eles não possam ser expressos em termos quantitativos (Pfeiffer, 2000).

\subsubsection{Diretrizes organizacionais}

Para Rezende e Castor (2006), as diretrizes estão relacionadas com traçados de caminhos, com programas de atividades, com conjunto de instruções, com indicações de ações e com normas ou procedimentos. São as linhas que definem e norteiam o futuro da cidade, bem como as políticas, valores, princípios e objetivos a serem definidos. Pode-se também considerar as diretrizes como os rumos, os processos, as linhas estratégicas e os objetivos a serem trabalhados.

a) Missão: como metodologia, definir missão e valores significa adotar uma referência para direcionar análises e cenários posteriores. A missão comunica um sentido de propósito, uma vez que cria uma linguagem própria e uma forma de comunicação entre gestores, funcionários e o público externo. Para o autor, uma missão bem definida é um instrumento valioso para o incentivo do uso de novas modalidades de ação e de novos instrumentos adminis- 
trativos (Motta, 2004). A missão organizacional, nas palavras de Certo e Peter (1993), é a proposta ou a razão pela qual uma organização existe, contribuindo para a concentração do esforço, direção comum, base lógica para alocar recursos organizacionais, e atua como base para o desenvolvimento de objetivos organizacionais.

b) Objetivos estratégicos: o objetivo estratégico prevê uma posição de liderança desejada e estabelece os critérios que a organização utilizará na representação desse progresso. Engloba ainda um processo de gestão ativa que inclui: focar a atenção da organização na essência da vitória; motivar pessoas ao comunicar o valor da meta; deixar espaço para contribuições individuais e de equipes; sustentar o entusiasmo fornecendo definições para novas operações à medida que as circunstâncias mudam; e usar consistentemente o objetivo para guiar as alocações de recursos. O objetivo estratégico captura a essência da vitória; é estável; estabelece uma meta que justifica esforço pessoal e comprometimento (Mintzberg et al., 2006).

Segundo Pagnoncelli e Aumond (2004), os objetivos são resultados, desafios que a cidade precisa atingir, num prazo determinado, para concretizar sua visão e incluem indicadores para a avaliação de seu desempenho. Enquanto a visão tradicional de estratégia se concentra no grau de ajuste entre os recursos existentes e as oportunidades atuais, o objetivo estratégico cria uma falta de ajuste extrema entre recursos e ambições (Mintzberg et al., 2006). Para Drucker (1954), as organizações devem planejar a realização de diversos objetivos em vez de se limitar a um único. Devem ser especificados objetivos suficientes para que todas as áreas importantes ao funcionamento da empresa sejam envolvidas. Propõe que os objetivos organizacionais devem abordar as seguintes áreas-chave: posição de mercado; inovação; produtividade; níveis de recursos; lucratividade; desempenho e desenvolvimento do administrador; desempenho e atitude do empregado e responsabilidade social.

\subsubsection{Implementação da estratégia}

Considera-se como estratégia operacional o preconizado por Johnson e Scholes (1999), os quais classificam as estratégias em grandes corporações por meio de três níveis: a estratégia corporativa, a estratégia da unidade de negócios e a estratégia operacional. Nesse contexto, a estratégia operacional está relacionada à forma como os componentes da organização, em termos de recursos, processos, pessoal e suas habilidades, efetivamente vão contribuir para direcionar a empresa na direção das estratégias da unidade de negócios e corporativa. Compreende uma série de subatividades primariamente administrativas. Se o objetivo é determinado, então é possível mobilizar os recursos da organização para atingi-lo (Mintzberg et al., 2006).

Priorizou-se neste estudo, para fins de oportunizar uma análise comparativa quando da realização do estudo de caso, três estratégias operacionais assim constituídas: descentralização; intersetorialidade; e participação social. 
a) Descentralização

Segundo Junqueira (1998), a descentralização é um fenômeno que pautou a administração pública do final do século XX. A utilização da descentralização como estratégia de mudança nas relações entre Estado e sociedade teve início nos anos 1970 pelos países centrais democráticos, como alternativa à crise do estado do bem-estar social, cujo modelo, além de ocasionar expansão do aparato burocrático, também gerou acentuada centralização das decisões e comprometimento de sua eficácia. Nesse contexto, emergiu a demanda por reformas administrativas do aparelho estatal para que esse pudesse aprimorar seu funcionamento em termos de eficácia, eficiência e abertura do processo decisório perante a sociedade, no que se refere à questão de políticas sociais. O princípio da gestão descentralizada, de modo integrado, colegiado e participativo, ainda se encontra no estágio inicial e os entraves são significativos e diferenciados. A mudança de paradigma e os desafios que se apresentam para a implementação de práticas participativas estão intimamente relacionados com o papel dos gestores e a lógica do atual sistema (Jacobi, 2000).

Para Pimenta (1995), a descentralização na administração pública pode se manifestar nos seguintes sentidos: descentralização interna, ou intragovernamental, que ocorre dentro de uma mesma estrutura administrativa, de cima para baixo; de dentro para fora da organização estatal, em que se considera a parceria com a sociedade, terceirização, descentralização para organizações não governamentais (ONGs) e outras organizações e privatização; e a descentralização intergovernamental, em que se tem a federalização, municipalização e microrregionalização. Para Araújo (2002), a descentralização representa uma efetiva mudança da escala de poder, conferindo às unidades comunitárias e municipais capacidade de escolha e definição sobre suas prioridades e diretrizes de ação e sobre a gestão de programas e projetos. É vista como um processo de transferência da autoridade e do poder decisório de instâncias mais elevadas para instâncias menores, entre as quais o município e as comunidades, conferindo capacidade de decisão e autonomia de gestão para as unidades.

Jacobi (2000) classifica o processo de descentralização tomando por referência o grau de poder político que é transferido da seguinte maneira: desconcentração, delegação ou devolução. Desconcentração é a redistribuição do poder decisório entre os diversos níveis do governo central; delegação é a transferência de responsabilidades e de poder do governo central para organizações semiautônomas (órgãos públicos) que não são totalmente controladas pelo governo central, mas que em última instância dele dependem; e devolução, que se constitui na transferência de poderes do governo central para unidades subnacionais independentes.

b) Intersetorialidade

A intersetorialidade é uma prática social que vem sendo construída com base na existência de profundas insatisfações, principalmente no que se refere à capacidade das organizações em dar resposta às demandas sociais e aos problemas complexos vivenciados pelos cidadãos (Ckagnazaroff e Motta, 2003). A intersetorialidade pode ser considerada uma lógica para a gestão da cidade, visando a superação da segmentação e setorização das políticas públicas, numa tentativa de considerar o cidadão em sua totalidade, em suas necessidades individuais e coletivas, em que, para usufruir uma vida com qualidade, necessita que seus problemas sejam 
tratados como eles se apresentam na realidade, ou seja, em sua totalidade e não de forma fragmentada (Junqueira, 1998).

Ckagnazaroff e Motta (2003), ao efetuarem uma analogia entre descentralização e intersetorialidade, afirmam que com a distribuição dos serviços prestados pelo governo local, via descentralização, é possível uma melhoria na execução das políticas públicas, haja vista a maior proximidade com o cidadão e uma visão mais completa de suas necessidades. A descentralização consiste numa visão integrada dos problemas vivenciados pelos cidadãos. Com uma ação sinérgica entre os vários departamentos responsáveis pelos serviços prestados pelo governo municipal evita-se a fragmentação da atenção às necessidades sociais e o paralelismo de ações, sendo possível um tratamento mais eficiente dos problemas complexos da sociedade e oferecer, assim, melhor qualidade de vida para a população.

Com base numa abordagem intersetorial, percebe-se que os problemas da sociedade devem ser considerados como um conjunto único, da maneira como se apresentam no cotidiano da sociedade, e que pressupõe a articulação de saberes e experiências que se encontram estruturados na sociedade de forma fragmentada. Uma atuação intersetorial caracteriza-se, ainda, como uma atuação em rede, entendida aqui como um arranjo entre pessoas, órgãos, departamentos, divisões, organizações etc. No entanto, vê-se que eles se apresentam de um modo em que o Estado, ou qualquer outra organização, sozinhos, e com conhecimentos especializados e fragmentados, não conseguiriam solucioná-los em virtude da complexidade de como eles são percebidos na sociedade. Nesse ponto, o conceito de rede pode ser útil, já que vincula atores em torno de diferentes aspectos de um problema em um determinado segmento da sociedade (Ckagnazaroff e Motta, 2003).

\section{c) Participação social}

A participação popular na gestão das cidades emergiu, primeiramente, como uma possibilidade de duplo poder, sobretudo no Brasil dos anos 1980, recém-egresso de um regime cujos mecanismos de representação, além de limitados, eram atacados frontalmente, cada vez que os resultados eleitorais pareciam ameaçar sua continuidade (Neto e Araújo, 1998). Adquire maior consistência e visibilidade com o retorno da democracia representativa, ocorrido a partir da década de 1980, se fazendo presente nos novos modelos de gestão, em que a própria Constituição de 1988 incorporou o princípio da participação popular direta na administração pública e ampliou a cidadania política (Benevides, 1991).

Desenha-se, assim, um cenário no qual o desafio é incorporar os atores locais à concepção e sustentação do processo de desenvolvimento. O planejamento do centro para as unidades subnacionais, aspecto do desenvolvimentismo do século XX, perde força, fazendo com que os gestores públicos sejam obrigados a formular políticas capazes de articular os sujeitos locais fortalecidos em sua autonomia, e produzam um projeto estratégico de desenvolvimento regional e de inserção cooperativa e interdependente (Genro, 2000).

Na rotina da administração municipal, verificou-se que o recurso à participação popular, mesmo servindo para impactar positivamente a máquina administrativa, muitas vezes poderia atuar também como um complicador, pois, ao invés de agilizar, podia dificultar ainda mais a máquina burocrática. Ao abrir espaços para o confronto de interesses divergentes, a prática da 
democracia semidireta, numa sociedade marcada por fortes desigualdades socioeconômicas, pode acirrar os conflitos, em vez de viabilizar soluções negociadas (Neto e Araújo, 1998).

Trata-se, principalmente, de superar o estágio centralizador de tomada de decisões e formas de intervenção que não levem em conta as diferenças, inibam iniciativas e ignorem as preferências dos grupos sociais envolvidos, implantando mecanismos democráticos e cooperativos de formulação, implementação, monitoramento e avaliação de políticas, programas e projetos. Cumpre, portanto, estabelecer sistemas de cooperação e apoio mútuo entre esferas governamentais, resguardando a integração nacional e estimulando parcerias estratégicas, no espírito de uma federação corporativa. Sem essa preocupação não se conseguirá alcançar o consenso e a mobilização social indispensáveis à eficiência, eficácia e efetividade de qualquer projeto de desenvolvimento local endógeno (Costa e Cunha, 2004). Participar é um ato de escolha, é um processo de aprendizagem. Quando as pessoas descobrem que podem contribuir para a construção de uma sociedade e que isso depende de sua vontade e de suas escolhas, a democracia pode se tornar realidade, dando oportunidades aos cidadãos de participarem da vida pública, criando uma cultura participativa, transparente e responsável (Bordenave, 1995).

\subsubsection{Controles estratégicos}

Segundo alguns autores, o controle estratégico se encontra inserido no contexto da implementação das estratégias. Para fins de organização didática deste estudo, optou-se em considerá-lo uma categoria específica, com foco de análise no monitoramento e avaliação da gestão municipal. Seu principal objetivo é realimentar os tomadores de decisões, de forma que possam corrigir ou reforçar esse desempenho ou interferir em função do processo administrativo, para assegurar que os resultados satisfaçam às metas, aos desafios e aos objetivos estabelecidos. Segundo a concepção de Oliveira (2003), o controle pode ser considerado uma função do processo administrativo que, mediante a comparação com padrões previamente estabelecidos, procura medir e avaliar o desempenho e o resultado das ações. Nessa perspectiva, o produto final do processo de controle são a informação e seus sistemas, que permitam constante e efetiva avaliação.

Pode ser considerado, também, um tipo especial de controle organizacional que se concentra na monitoração e avaliação do processo de administração estratégica para melhorá-lo e assegurar um funcionamento adequado. Para realizar com êxito essa tarefa, os administradores devem compreender o processo de controle estratégico e os papéis das auditorias estratégicas (determinação do ambiente organizacional). Além disso, é necessária a compreensão dos meandros dos sistemas de informações da administração e a forma como tal sistema possa complementar o processo de administração estratégica (Certo e Peter, 1993).

\section{Metodologia de pesquisa}

Para fins de realização desta pesquisa, optou-se pelo estudo de caso como fonte de pesquisa da realidade envolvida. Classifica-se como documental uma vez que se baseou em observa- 
ções diretas do plano de governo das gestões analisadas, em relatórios de gestão, relatórios anuais, materiais de divulgação e demais publicações elaboradas pelo Instituto de Pesquisa e Planejamento Urbano de Curitiba (IPPUC) e pelo Instituto Municipal de Administração Pública (Imap). Para fins de realização desta pesquisa, definiu-se como caso único o município de Curitiba, tendo como recorte analítico as gestões compreendidas no intervalo de tempo compreendido entre 1993-96; 2000-04 e 2005-08. Para que a análise dos dados da pesquisa fosse viabilizada, foi necessário pesquisar e definir variáveis (ou critérios) para direcionar e interpretar seus resultados. Essas variáveis são partes fundamentais do protocolo da pesquisa, no qual foi estabelecida uma relação entre as variáveis e os autores que as fundamentam, bem como as respectivas questões de análise. O protocolo da pesquisa contempla seis variáveis, as quais compõem as etapas do processo de administração estratégica, quais sejam: formulação das estratégias com a subvariável projetos estratégicos; formalização das estratégias com as subvariáveis fases do planejamento e pressupostos metodológicos; análises do ambiente com a subvariável diagnóstico municipal; diretrizes organizacionais com as subvariáveis missão e objetivos estratégicos; implementação da estratégia com as subvariáveis intersetorialidade, descentralização e participação social; e controles estratégicos com as subvariáveis monitoramento e avaliação da gestão. O presente estudo constitui parte integrante do projeto de pesquisa iniciado em outubro de 2006 junto a um programa de pós-graduação stricto sensu.

\section{Análises e conclusão}

O governo municipal, na atualidade, sofre pressões para fazer mais e melhor. A gestão pública demandada pelo novo modelo requer gestão compartilhada, democratização de centros decisórios, modernização nas estruturas, métodos e processos flexíveis, descentralização, intersetorialidade, agilidade, e, acima de tudo, visão e pensamento estratégicos. Essas demandas, por sua vez, sinalizam para governantes e gestores a necessidade de aperfeiçoar os meios de gerir e integrar ações de governo, lançando mão de métodos e estratégias diferenciadas e inovadoras. Nesse contexto, a administração estratégica pode se constituir num dos recursos a serem utilizados pelos governos locais permitindo responder à aceleração das mudanças nas condições socioeconômicas, sociopolíticas e culturais. Ao considerar as etapas da administração estratégica identificadas nas gestões municipais priorizadas nesse estudo, concluiu-se que o município em questão possui, ao menos na perspectiva teórica, uma gestão estratégica. Isso fica evidenciado na existência de planejamento, vinculado ao diagnóstico municipal, em consonância com as diretrizes e estratégias municipais e complementados com a utilização de instrumentos de monitoramento e avaliação da gestão.

O quadro 2 sintetiza uma série histórica das etapas do processo de administração estratégica identificadas, cuja elaboração teve por base de análise as gestões municipais de Curitiba, compreendidas no intervalo de tempo: 1993-96; 2000-04 e 2005-08, quando da realização deste estudo. Objetivou-se por meio da elaboração desse quadro destacar, na perspectiva de um continuum, a manutenção dos processos, as implementações ocorridas, as inovações e as respectivas rupturas verificadas. Tendo por elemento balizador o objetivo definido, utilizou-se as categorias e subcategorias de análise definidas quando da elaboração do protocolo de pesquisa. 


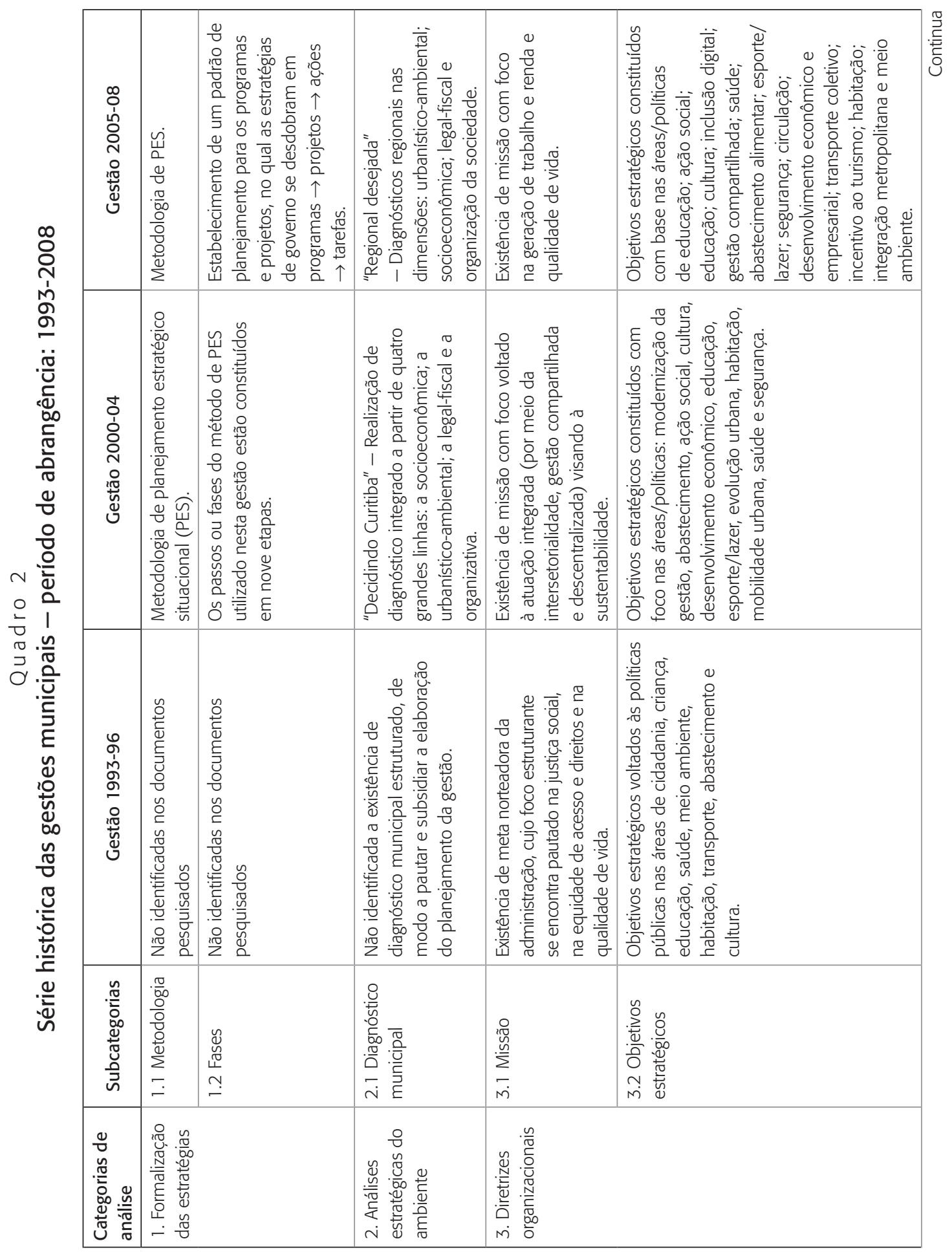

RAP - Rio de Janeiro 46(3):795-816, maio/jun. 2012 


\begin{tabular}{|c|c|c|c|c|c|}
\hline 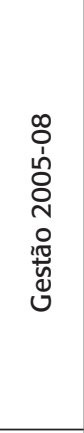 & 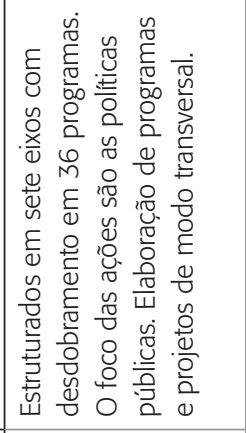 & 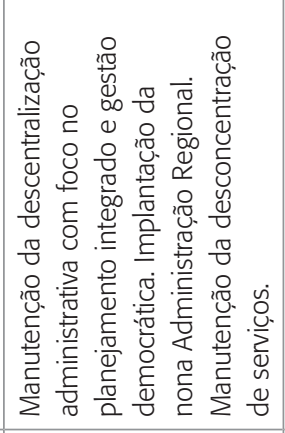 & 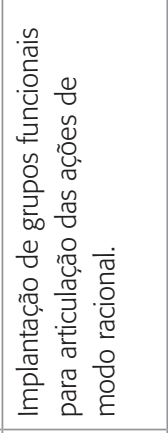 & 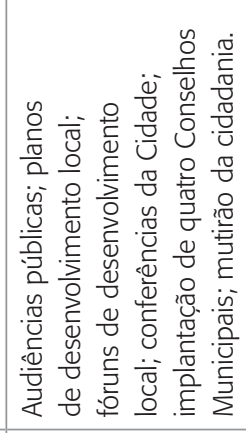 & 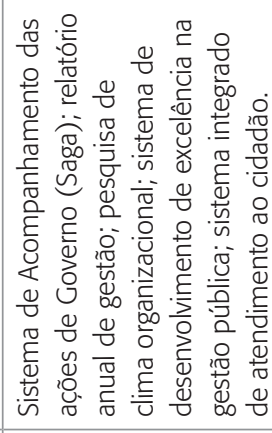 \\
\hline 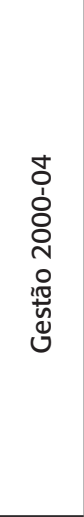 & 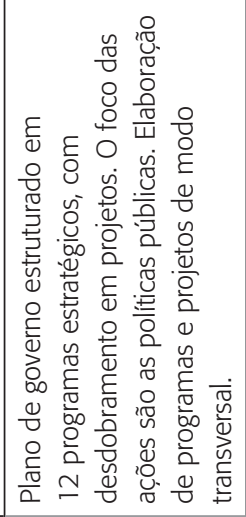 & 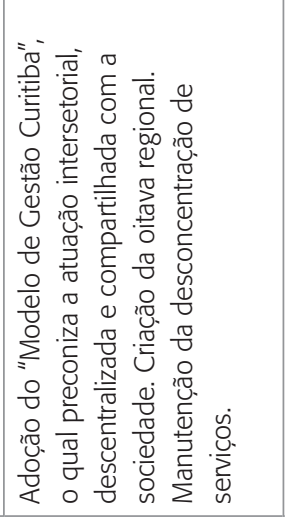 & 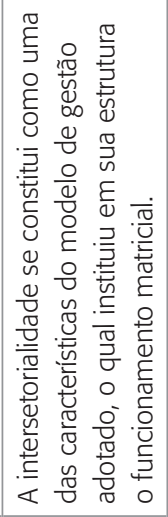 & 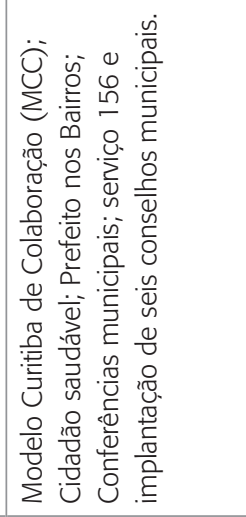 & 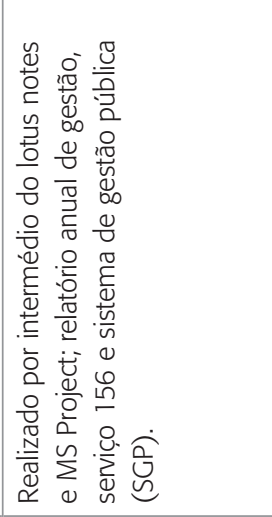 \\
\hline 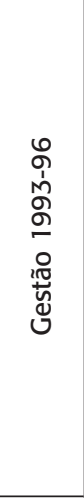 & 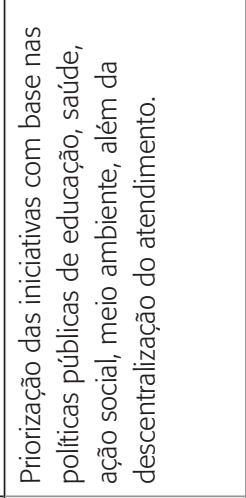 & 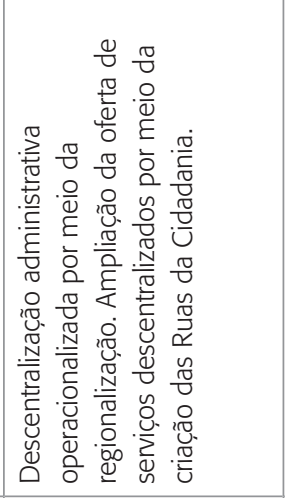 & 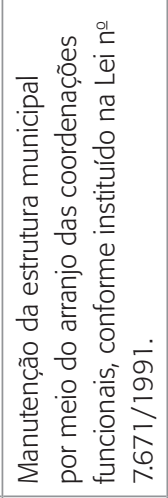 & 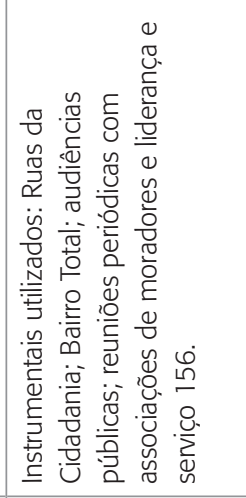 & 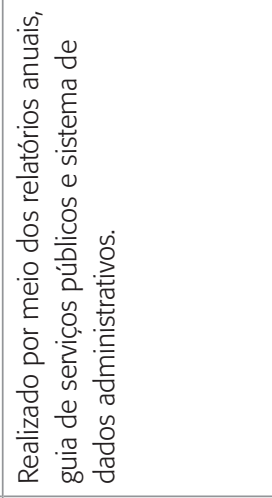 \\
\hline 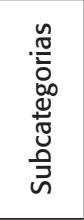 & 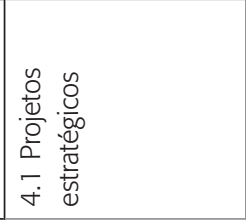 & 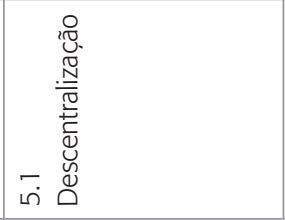 & 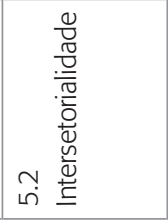 & 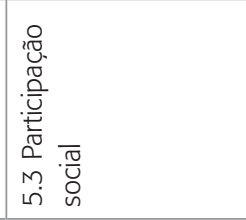 & 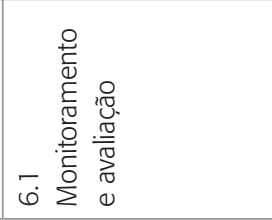 \\
\hline 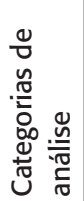 & 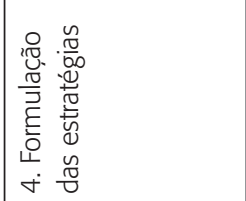 & 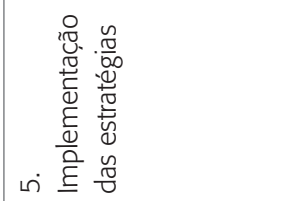 & & & 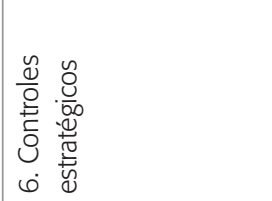 \\
\hline
\end{tabular}

RAP - Rio de Janeiro 46(3):795-816, maio/jun. 2012 
Tal conclusão possibilitou a proposição de um modelo de gestão da estratégia, resultante da combinação das categorias de análise que compuseram este estudo, e que representa, em sua concepção, um potencial ferramental a ser utilizado pelos gestores locais como alternativa de implementação do processo de gestão.

Nessa perspectiva, a figura a seguir demonstra que a gestão municipal de estratégia é resultante da integração e combinação de ao menos seis etapas ou fases: formalização das estratégias; formulação das estratégias; análises estratégicas do ambiente; diretrizes organizacionais; implementação das estratégias e controles estratégicos.

Em consonância com esse modelo, a formalização das estratégicas constitui o processo de ordenação das atividades governamentais num conjunto harmônico de decisões, que permitam ao município o alcance de determinados objetivos.

As análises estratégicas do ambiente, focadas na realização de diagnóstico municipal, oportunizam uma leitura, caracterização e priorização do cenário externo, que se constitui objeto de intervenções municipais.

As diretrizes organizacionais, compostas pela missão e objetivos estratégicos, representam as linhas estratégicas que definem e norteiam o rumo do município.

Em se tratando da formulação das estratégias, essa é caracterizada por meio de projetos, os quais expressam a intenção estratégica da Prefeitura e elenca e prioriza as áreas de atuação e alocação de recursos.

No que se refere à implementação das estratégias, este modelo (figura) lança mão da intersetorialidade, da descentralização das ações e da participação social como recurso para pôr em prática as estratégias desenvolvidas. Para finalizar e concluir o modelo de estratégia proposto deve-se ressaltar a importância e pertinência dos controles, aqui considerados instrumentos de monitoramento e avaliação da gestão, visando à aferição e avaliação do desempenho e do resultado das ações, os quais geram insumos para a retroalimentação do processo.

\section{Figura}

\section{Proposta de modelo de gestão da estratégia}

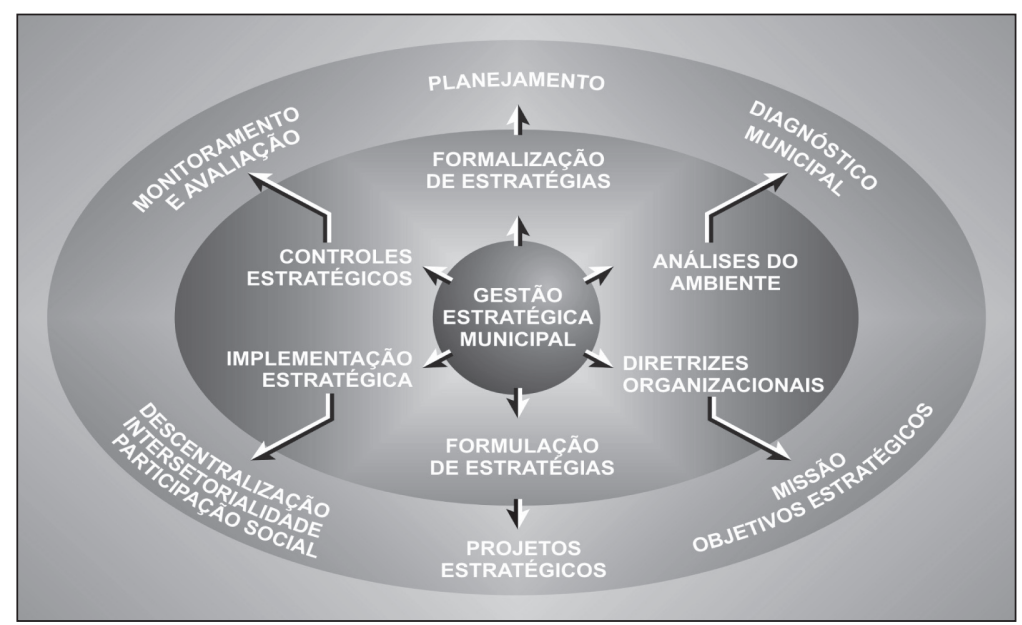

Fonte: Elaborada pelos autores com base na fundamentação teórica e na pesquisa documental da Prefeitura Municipal de Curitiba. 
Constituiu objetivo deste artigo propor um modelo de gestão de estratégia, concebido como ferramenta de gestão para os governo locais, resultante da combinação das categorias e subcategorias que compuseram este estudo, as quais foram definidas tendo por base as etapas do processo de administração estratégica. Acredita-se que o mesmo foi cumprido, uma vez que por meio de uma visão sistêmica e integradora apresentou-se a proposição de um modelo de gestão de estratégia, passível de adaptações e ajustes às realidades locais. Estimula ainda o processo de gestão do conhecimento entre as prefeituras, por meio do compartilhamento de conhecimentos e troca de experiências.

No que tange às contribuições deste estudo, elas estão direcionadas para a academia, para os gestores e para outras organizações públicas.

Para a academia, uma vez que as estratégias utilizadas pelas gestões estudadas podem motivar estudos posteriores e aprofundamentos teóricos complementares, ao se considerar que a análise da administração estratégica, seus impactos na gestão municipal e respectivos indicadores se constituem num amplo caminho a ser trilhado e mais bem explorado pela academia. Acredita-se também que este estudo possa ser de alguma valia para os gestores municipais, ao se constituir numa ferramenta de fácil utilização e adaptação às necessidades e interesses locais. Finalmente, este estudo pode contribuir com outras organizações públicas diante da possibilidade de que as estratégias aqui apresentadas possam ser replicadas e estendidas a outras realidades, de modo a subsidiar a adoção de métodos efetivos de gestão. Contribui também com a explicitação das novas competências necessárias a serem desenvolvidas nas equipes municipais diante do contexto abordado.

Apesar de não comprometerem este estudo, identificou-se a existência de algumas limitações, as quais ocorreram, inicialmente, em virtude de o mesmo ser classificado como documental, em que não se utilizou de outros procedimentos para a coleta de dados, fato que poderia enriquecer e complementar os dados e informações obtidos. Outro aspecto limitador foi a realização de estudo de caso único, impossibilitando a análise comparativa entre municípios, bem como a replicação e o compartilhamento das estratégias a outras realidades.

\section{Referências}

ANSOFF, H.I. Administração estratégica. São Paulo: Atlas, 1983.

ANSOFF, H.I.; McDONNELL, E.J. Implantando a administração estratégica. 2. ed. São Paulo: Atlas, 1993.

ARAÚJO, T.B. Descentralização e participação na reforma agrária. In: SEMINÁRIO SOBRE REFORMA AGRÁRIA E DESENVOLVIMENTO SUSTENTÁVEL, Fortaleza, 2002. Disponível em: <www.nead. gov.br>. Acesso em: 15 jun. 2007.

BENEVIDES, M.V. A cidadania ativa: referendo, plebiscito e iniciativa popular. São Paulo: Ática, 1991.

BORDENAVE, J.E.D. O que é participação. São Paulo: Brasiliense, 1995. 
CABRAL, J.B. O município e a cidadania: seleção de textos para o administrador público e o cidadão. Brasília: Senado Federal, 1996.

CASTELLS, M.; BORJA, J. As cidades como atores políticos. Novos Estudos Cebrap, São Paulo, n. $45,1996$. p. 153-174.

CASTRO JUNIOR, O.A. Aspectos jurídicos da gestão municipal. Disponível em: <www.ibradd.com. br>. Acesso em: 14 jan. 2008.

CERTO, S.; PETER, P. Administração estratégica: planejamento e implantação da estratégia. São Paulo: Makron Books, 1993.

CHANDLER JR., A.D. Strategy and structure. Cambridge: MIT Press, 1962.

CHRISTENSEN, K.H. Estratégia corporativa: gerenciando um conjunto de negócios. In: FAHEY, L.; RANDALL, R.M. MBA curso prático: estratégia. 2. ed. Rio de Janeiro: Campus, 1999. p. 67-99.

CKAGNAZAROFF, I.B.; MOTTA, N.R. Considerações sobre a relação entre descentralização e intersetorialidade como estratégias de modernização de prefeituras municipais. E \& G Economia $e$ Gestão, Belo Horizonte, v. 3, n. 6, p. 23-41, 2003.

COSTA, F.L.; CUNHA, A.P.G. Pensar o desenvolvimento a partir do local: novo desafio para os gestores públicos. In: VERGARA, S.C.; CORRÊA, V.L.A. (Org.). Propostas para uma gestão pública municipal efetiva. 2. ed. Rio de Janeiro: Editora FGV, 2004. p. 217-221.

DRUCKER, P.F. The practice of management. New York: Harper \& Row, 1954.

FACHIN, R.; CHANLAT, A. Governo municipal na América Latina: inovações e perplexidades. Porto Alegre: Sulina/Editora da UFRGS, 1998.

FIGUEIREDO, R.; LAMOUNIER, B. As cidades que dão certo: experiências inovadoras na administração pública brasileira. Brasília: MH Comunicação, Brasília, 1996.

FREY,K. Gestão urbana: um desafio interdisciplinar. In: SEMINÁRIO INTERNACIONAL EM GESTÃO URBANA, I, Curitiba, 2003. Anais... PUCPR/PPGTU, 2003. v. 1, p. 165-185.

GENRO, T. Os gestores públicos e as demandas futuras. Revista Eletrônica de Administração — REAd, Porto Alegre, v. 6, n. 3, 2000. Entrevista.

JACOBI, P.R. Políticas sociais e ampliação da cidadania. Rio de Janeiro: Fundação Getulio Vargas, 2000.

JOHNSON, G.; SCHOLES, K. Exploring corporate strategy: text and cases. 5th. ed. New York: Prentice-Hall, 1999.

JUNQUEIRA, L.A.P. Descentralização e intersetorialidade: a construção de um modelo de gestão municipal. Revista de Administração Pública, Rio de Janeiro, v. 32, n. 2, p. 35-48, 1998.

LLONA, M.; LUYO, M.; MELGAR, W. La planificación estratégica del desarollo local em Peru: análisis de casos. Lima: Escuela, 2003.

LODI, J.B. Estratégia de negócios: planejamento a longo prazo. Revista de Administração de Empresas, Rio de Janeiro, v. 9, n. 1, p. 5-32, 1969. 
LOPES, R. A cidade intencional: o planejamento estratégico de cidades. Rio de Janeiro: Mauad, 1998.

MACHADO, G. Reinventando o Estado: uma reflexão sobre as ideias de Osborne. In: MACHADO, G. et al. A gestão pública: desafios e perspectivas. Salvador: Fundação Luiz Eduardo Magalhães (Flem), 2001.

MARINI, C. Gestão pública: o debate contemporâneo. Salvador: Fundação Luiz Eduardo Magalhães, 2003.

MATIAS-PEREIRA, J. Curso de administração pública: foco nas instituições e ações governamentais. São Paulo: Atlas, 2008.

MEIRELLES, A.M.; GONÇALVES, C.A. O que é estratégia: histórico, conceito e analogias. In: GONÇALVES, C.A.; REIS, M.T.; GONÇALVES, C. (Org.). Administração estratégica: múltiplos enfoques para o sucesso empresarial. Belo Horizonte: UFMG/Cepead, 2001.

MICHEL, K. Esboço de um programa de desenvolvimento administrativo intrafirma para a administração estratégica. In: ANSOFF, H.; DECLERCK, R.; HAYES, R. (Org.). Do planejamento estratégico à administração estratégica. São Paulo: Atlas, 1990.

MINTZBERG, H. et al. O processo da estratégia: conceitos, contextos e casos selecionados. 4. ed. Porto Alegre: Bookman, 2006.

MINTZEBERG, H.; AHLSTRAND, B.; LAMPEL, J. Safári da estratégia. Porto Alegre: Bookmann, 2000 .

MINTZBERG, H.; QUINN, J.B. O processo da estratégia. 3. ed. Porto Alegre: Bookman, 2001.

MONTGOMERY, C.A.; PORTER, M.E. Estratégia: a busca da vantagem competitiva. Rio de Janeiro: Campus, 1998.

MOTTA, F.C.P. Gestão contemporânea: a ciência e a arte de ser dirigente. 8. ed. Rio de Janeiro: Record, 1997.

MOTTA, P.R. Gestão estratégica. In: VERGARA, S.C.; CORRÊA, V.L.A. (Org.). Propostas para uma gestão pública municipal efetiva. 2. ed. Rio de Janeiro: Editora FGV, 2004. p. 69-88.

NETO, L.G.; ARAÚJO, T.B. Poder local, governos municipais e políticas de indução do desenvolvimento econômico no Brasil. In: SOARES, J.A.; CACCIA-BAVA, S. (Org.). Os desafios da gestão municipal democrática. São Paulo: Cortez, 1998. p. 35-48.

OLIVEIRA, D.P.R. Planejamento estratégico: conceitos, metodologias e práticas. 19. ed. São Paulo: Atlas, 2003.

PACHECO, R.S. Administração pública gerencial: desafios e oportunidades para os municípios brasileiros. In: FUNDAÇÃO PREFEITO FARIA LIMA. O município no século XXI: cenários e perspectivas. São Paulo: Cepam, 1999.

PAGNONCELLI, D.; AUMOND, C.W. Cidades, capital social e planejamento estratégico: o caso Joinville. Rio de Janeiro: Elsevier, 2004. 
PFEIFFER, P. Planejamento estratégico municipal no Brasil: uma nova abordagem. Brasília: Enap, 2000. (Textos para Discussão, n. 37).

PIMENTA, Carlos César. Novos modelos de gestão descentralizada e de parcerias para as administrações estaduais. Revista de Administração Pública, Rio de Janeiro, v. 29, n. 3, p. 171-187, jul./set. 1995.

PORTER, M. Competição — on competition: estratégias competitivas essenciais. Rio de janeiro: Campus, 1999.

REZENDE, D.A.; CASTOR, B.V.J. Planejamento estratégico municipal: empreendedorismo participativo nas cidades, prefeituras e organizações públicas. 2. ed. Rio de Janeiro: Brasport, 2006.

REZENDE, D.A.; FREY, K. Administração estratégica e governança eletrônica na gestão urbana. Revista Gesta - Revista Eletrônica de Gestão Portuária, Ambiental e de Negócios, Santos, v. 0, p. 1118, maio 2005.

ROSSI, L.C. et al. Gestão pública municipal: ideias e práticas para prefeitos, gestores e técnicos. Mato Grosso do Sul: Letra Livre, 2004.

SILVA JUNIOR, N.A.; LEAL, P.R.G.; SHIGUNOV, T. O cadastro técnico como ferramenta para a gestão urbana. In: CONGRESSO BRASILEIRO DE CADASTRO TÉCNICO MULTIFINALITÁRIO (COBRAC 2004), Florianópolis, 2004.

SOUZA, A.C.S. de; REZENDE, D.A.; HARDT, C. Estratégia, planejamento de municípios e gestão metropolitana. RAI — Revista de Administração e Inovação, São Paulo, v. 4, n. 1, p. 21-39, 2007.

SOUZA, M.L. Mudar a cidade: uma introdução crítica ao planejamento e à gestão urbanos. 3. ed. Rio de Janeiro: Bertrand Brasil, 2002.

STOKER, G. Urban political science and the challenge of urban governance. In: PIERRE, Jon (Ed.). Debating governance: authority, steering and democracy. New York: Oxford University Press, 2000, p. 91-109.

SVEIBY, KE. A nova riqueza das organizações. Rio de Janeiro: Campus, 1998.

VERGARA, S.C. Características do mundo contemporâneo e as repercussões na gestão municipal. In: VERGARA, S.C.; CORREAA, V.L.A. Gestão pública municipal efetiva. 2. ed. Rio de Janeiro: Editora FGV, 2004. p. 1-9.

WRIGHT, P.; KROLL, M.; PARNELL, J. Administração estratégica: conceitos. São Paulo: Atlas, 2000 .

Francine Lia Wosniak é mestranda do Programa de Mestrado e Doutorado em Gestão Urbana da Pontifícia Universidade Católica do Paraná (PUC-PR).E-mail: franwosniak@ig.com.br.

Denis Alcides Rezende é professor do Programa de Mestrado e Doutorado em Gestão Urbana da PUC-PR. E-mail: denis.rezende@pucpr.br. 